\title{
Early and severe sensory loss in three adult siblings with hexosaminidase A and B deficiency (Sandhoff disease)
}

\author{
H Schnorf, R Gitzelmann, N U Bosshard, M Spycher, W Waespe
}

\begin{abstract}
Three siblings in their sixth and seventh decade with hexosaminidase $A$ and $B$ deficiency (adult form of $\mathbf{G}_{\mathrm{M}_{2}}$-gangliosidosis, variant $O)$ developed early and severe sensory loss in addition to chronic motor neuron disease and cerebellar ataxia. Prominent mechanoallodynia was a manifesting symptom in two siblings. It is suggested that sensory deficits are due to a central-peripheral dying back axonopathy. The early and dominant sensory disturbances extend the clinical range of $G_{M 2}$-gangliosidosis.
\end{abstract}

(F Neurol Neurosurg Psychiatry 1995;59:520-523)

Keywords: hexosaminidase deficiency; adult $\mathrm{G}_{\mathrm{M} 2}$-gangliosidosis; polyneuropathy; motor neuron disease; cerebellar atrophy

$\mathrm{G}_{\mathrm{M} 2}$-gangliosidosis is an inherited lipid storage disease characterised by the accumulation mainly of $\mathrm{G}_{\mathrm{M} 2}$-gangliosides in neuronal and non-neuronal tissues. It is caused by deficient activity of the lysosomal enzyme hexosaminidase $A$, by combined deficiencies of both isoenzymes hexosaminidase $A$ and $B$, or a deficiency of the $G_{M 2}$ activator protein. ${ }^{1-3}$ Motor neuron and cerebellar syndromes, often found in combination and sometimes associated with psychiatric manifestations, are the most common phenotypic presentations of the adult form of hexosaminase A deficiency ${ }^{4-11}$ and combined hexosaminase $A$ and B deficiencies. ${ }^{12-19}$ Polyneuropathy has been reported both in hexosaminase A deficiency $\mathrm{y}^{4-5}$ and hexosaminase A and B deficiency. ${ }^{12-18}$ It was clinically insignificant, however, in most reported cases, ${ }^{4-515-18}$ and major sensory loss was exceedingly rare. ${ }^{12-14}$

We report the findings in three siblings in their sixth and seventh decades with early onset and severe multimodal sensory loss in addition to a chronic motor neuron and cerebellar syndrome, who had severly reduced hexosaminase A and B activity in their serum, leucocytes, and cultured fibroblasts. Prominent mechanoallodynia was the main manifesting symptom in two siblings, extending the phenotypic presentation of $\mathrm{G}_{\mathrm{M} 2}$-gangliosidosis.

\section{Case reports}

The siblings were of non-consanguinous Swiss-German origin. The father was reported as having longstanding tremor of the hands, but details are not available. A 66 year old fourth sibling had mechanoallodynia, sensory loss in the legs, and limb girdle weakness, but could not be examined in detail. The two next generations (eight children aged 25-47 years and 12 grandchildren) were asymptomatic.

\section{PATIENT 1}

A 59 year old man had developed proximal leg weakness at the age of 20 years, followed by increasing numbness in his lower legs and by intention tremor of the hands. At the age of 44, tendon reflexes were brisk, except for absent patellar tendon jerks. Plantar responses were flexor. There were fasciculations, atrophy, and moderate weakness of proximal limbs, especially of the quadriceps femoris muscles. Gait was ataxic. He had holding tremor of the arms. He had very reduced sensation for vibration and pain below the knees and, to a lesser degree, in the hands. Extensive laboratory investigation and CSF examination were normal. Needle EMG studies and biopsy of quadriceps femoris muscle were compatible with chronic denervation, and he was diagnosed as having spinal muscular atrophy of Kugelberg-Welander type and from essential tremor. Median and peroneal motor nerve conduction studies were normal at the age of 51 . Compound sensory potentials of the median nerve were reduced and split, and conduction velocity was slightly reduced $(42 \mathrm{~m} / \mathrm{s})$. Cranial MRI disclosed pronounced cerebellar atrophy. At the age of 59 he had normal intellect, speech, and cranial nerve functions. Limb girdle weakness was moderate to severe. He walked with a stick, had ataxia of trunk and gait, intention tremor, dysmetria of the arms, and severe arm holding tremor. Pain, position, and vibration sensation were lost below the knees and temperature sensation was moderately impaired. Vibration threshold was mildly reduced in the hands (table 1). Intrinsic hand and feet muscles were slightly amyotrophic and their skin was cold and bluish. Sensory nerve action potentials were not obtainable with skin electrodes from the peroneal and tibial nerves and were split and 
Table 1 Sensory loss in $G_{M 2}$-gangliosidosis (our patients and reported cases)

\begin{tabular}{|c|c|c|c|c|c|c|c|}
\hline Reference & $\begin{array}{l}\text { Enzyme } \\
\text { deficiency }\end{array}$ & Touch & Pain & Temperature & Vibration & fPS & Allodynia \\
\hline $\begin{array}{r}\text { This paper: } \\
\text { Patient } 1 \\
\text { Patient } 2 \\
\text { Patient } 2\end{array}$ & $\begin{array}{l}\text { Hex } A \text { and } B \\
\text { Hex } A \text { and } B \\
\text { Hex } A \text { and } B\end{array}$ & $\begin{array}{l}+ \\
+ \\
+\end{array}$ & $\begin{array}{l}+++ \\
++ \\
+\end{array}$ & $\begin{array}{l}l_{+} \\
++ \\
+++ \\
+++\end{array}$ & $\begin{array}{l}+++ \\
++ \\
+++\end{array}$ & $\begin{array}{l}+++ \\
+++\end{array}$ & $\begin{array}{l}- \\
+++ \\
+++\end{array}$ \\
\hline $\begin{array}{l}\text { Cashman et al }{ }^{12}(\mathrm{n}=1) \\
\text { Oonk et } \text { al }^{13} \text { and Bolhuis et al }{ }^{14}\end{array}$ & Hex A and B & - & +++ & +++ & - & - & NM \\
\hline $\begin{array}{l}(\mathrm{n}=2) \\
\text { Barbeau et al } l^{15}(\mathrm{n}=1) \\
\text { Mitsuo et al }{ }^{18}(\mathrm{n}=1)\end{array}$ & $\begin{array}{l}\text { Hex } A \text { and } B \\
\text { Hex } A \text { and } B \\
\text { Hex } A \text { and } B\end{array}$ & $\begin{array}{l}- \\
+ \\
-\end{array}$ & $\begin{array}{l}\overline{-} \\
\overline{-}\end{array}$ & $\begin{array}{l}- \\
\overline{-}\end{array}$ & $\begin{array}{l}+(+) \\
+ \\
+\end{array}$ & $\begin{array}{l}+ \\
- \\
-\end{array}$ & $\begin{array}{l}\text { NM } \\
\text { NM } \\
\text { NM }\end{array}$ \\
\hline Rapin et al ${ }^{5}(\mathrm{n}=3)$ & Hex A & - & - & - & - & - & t+ \\
\hline
\end{tabular}

Hex = Hexosaminidase; $\mathrm{n}=$ number of patients; JPS = joint position sense; NM = not mentioned; sensory loss ranged from none $(-)$ to severe $(+++)$.

of severly reduced amplitude in the median and ulnar nerves. Motor compound nerve potentials were normal with mildly diminished amplitudes. Tibial and median

T2 weighed fast spin echo midsagittal cervical spinal cord MRI section in a patient with adult Sandhoff disease (patient 1) showing generalised spinal cord atrophy $(A)$; transverse section at the cervical $5 / 6$ level shows flattening of the posterior contour, suggestive of posterior contour degeneration (B).
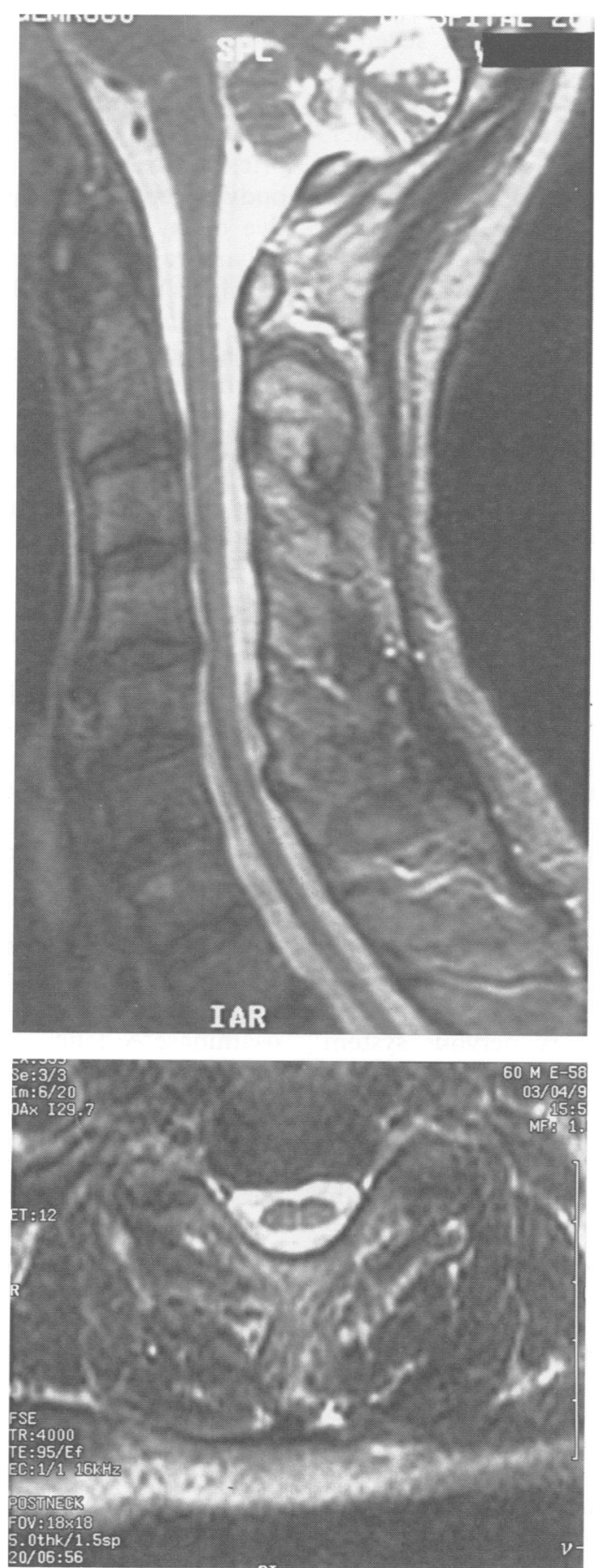

somatosensory evoked potentials were not reproducible at spinal levels. Cervical spine MRI disclosed atrophy of the cord, measuring $11 \mathrm{~mm}$ in the transverse plane and $7 \mathrm{~mm}$ in the sagittal plane, and there was flattening of the dorsal contour (figure, A, B).

\section{PATIENT 2}

From the age of six a 69 year old woman experienced a light touch to her lower legs as painful, so that, for example, she never wore high boots. At the same age she developed progressive proximal leg weakness and a writing tremor. In her mid-30s her legs began to feel "wooden", and the unpleasant feeling to touch became less intense. In her 50 s she noticed mild proximal arm weakness. At the age of 63 patellar and achilles tendon jerks were absent, and weak, respectively, and tendon reflexes in her arms were brisk. Plantar responses were flexor. She had pronounced proximal limb weakness and atrophy, especially of her legs and mild weakness of her foot flexor muscles. Dysmetria, ataxia, and holding tremor were present in her arms, and she had writing tremor. Below her knees temperature discrimination was absent, and pinprick and vibratory sensations were severely and moderately reduced respectively, whereas joint position sense was unaffected. Light touching of her lower legs was experienced as unpleasant or painful (table 1). Hands and feet showed amyotrophic changes and their skin was bluish. Needle electromyographic examination gave results similar to those in patient 1. Electroneurographic examination of leg motor nerves was normal. Cerebrospinal fluid was normal. At the age of 69 sensory abnormalities and leg weakness were more pronounced, with the exception of joint position sense, which remained normal.

\section{PATIENT 3}

A 65 year old woman had a history almost identical to that of her elder sister with respect to weakness and tremor. From her preteenage years on, touching of her lower legs elicited a painful sensation, and there was slowly progressive numbness and thermhypaesthesia in her legs. At the age of 64 tendon reflexes were brisk in the arms and depressed in the legs. Plantar responses were flexor. Fasciculation, pronounced atrophy, and weakness were present in proximal limb muscles, especially in the legs. There was dysmetria, intention tremor, and positioning tremor 
Table 2 Activities of $\beta$ hexosaminidase (patients)

\begin{tabular}{|c|c|c|c|c|}
\hline Enzyme & Controls range ( $n$ ) & Patient 1 & Patient 2 & Patient 3 \\
\hline $\begin{array}{l}\text { Serum }(\mathrm{nmol} / \mathrm{min} / \mathrm{ml}) \text { : } \\
\text { Hex A and } B^{\star} \\
\% \text { Hex A } \\
\text { Hex A† }\end{array}$ & $\begin{array}{c}11 \cdot 4-23 \cdot 0(40) \\
52 \cdot 7-77 \cdot 6(40) \\
2 \cdot 3 / 2 \cdot 7(2)\end{array}$ & $\begin{array}{r}2 \cdot 1 \\
96 \cdot 6 \\
0 \cdot 5\end{array}$ & $\begin{array}{r}2 \cdot 1 \\
85 \cdot 1 \\
0 \cdot 5\end{array}$ & $\begin{array}{r}1 \cdot 8 \\
80.5 \\
0.4\end{array}$ \\
\hline $\begin{array}{l}\text { Leucocytes (nmol/min } / \mathrm{mg} \text { protein): } \\
\text { Hex A and } B^{\star} \\
\% \text { Hex A } \\
\text { Hex At }\end{array}$ & $\begin{array}{c}10 \cdot 7-23 \cdot 8(10) \\
79 \cdot 4-88 \cdot 4(10) \\
2 \cdot 7-6 \cdot 6(33)^{23}\end{array}$ & $\begin{array}{r}2 \cdot 8 \\
92 \cdot 1 \\
1 \cdot 1\end{array}$ & $\begin{array}{r}1.6 \\
84.0 \\
0.5\end{array}$ & $\begin{array}{r}2 \cdot 8 \\
88 \cdot 3 \\
0 \cdot 9\end{array}$ \\
\hline $\begin{array}{l}\text { Fibroblasts (nmol/min } / \mathrm{mg} \text { protein): } \\
\text { Hex A and } B^{\star} \\
\% \text { Hex A } \\
\text { Hex A† }\end{array}$ & $\begin{array}{l}116 \cdot 448(11) \\
52 \cdot 2-72 \cdot 5(11) \\
51 \cdot 3-138(7)^{24}\end{array}$ & $\begin{array}{r}4 \cdot 8 \\
88 \cdot 2 \\
1 \cdot 3\end{array}$ & $\begin{array}{l}11 \cdot 8 \\
90 \cdot 2 \\
-\end{array}$ & $\begin{array}{l}10 \cdot 0 \\
93 \cdot 6 \\
-\end{array}$ \\
\hline
\end{tabular}

*Substrate: 4-methylumbelliferyl-N-acetyl- $\beta$-D-glucosaminide; †Substrate: 4-methylumbelliferyl- $\beta$-D-acetylglucosamine-6-sulphate. of her arms. Pinprick sensation and temperature discrimination were generally reduced, except in her face and on her back. Moreover, temperature sensation was virtually absent below her knees, with severely reduced pinprick and position and absent vibratory sensation. Slight touch to her lower legs was felt as painful and burning. In her hands vibratory sensation was moderately reduced and joint position sense was normal (table 1). Hands and feet were hypotrophic and their skin was bluish.

All three patients declined follow up electrophysiological studies and a sural nerve biopsy.

\section{BIOCHEMICAL STUDIES}

Hexosaminidase activities in serum, leucocytes, and cultured fibroblasts were low (table 2). In serum, leucocytes, and fibroblasts, and the reference enzymes-glucuronidase and galactosidase-were in the normal ranges in all three cases.

\section{ELECTRON MICROSCOPY}

Skin biopsy specimens were taken from the proximal inner part of the arm. Electron microscopic investigation showed rarification and atrophy of myelinated nerve fibres in all three patients. In patients 1 and 2 lamellated inclusion bodies with a periodicity of 5-7 nm were seen in Schwann cell cytoplasm and in eccrine sweat gland epithelial cells.

\section{Discussion}

Involvement of the sensory nervous system has been reported, both in hexosaminase $A$ deficiency $^{25}$ and in hexosaminase $A$ and $B$ deficiency (table 1). ${ }^{212-18}$ Sensory deficits were clinically almost always very mild, ${ }^{512-18}$ or detected only by electroneurography or by sural nerve biopsy. ${ }^{4}$ Our patients are exceptional, in so far as in two mechanoallodynia was the main presenting symptom, and in all three patients early and profound multimodal sensory loss developed (table 1). Similar mechanoallodynia, yet without associated sensory loss, was reported in three considerably younger patients with hexosaminase A deficiency. ${ }^{5}$ Electrophysiological studies in our patients and in other patients with hexosaminase A deficiency ${ }^{4}$ and hexosaminase A and B deficiency, ${ }^{4}{ }^{16-18}$ showed diminished amplitudes of sensory nerve potentials with relatively normal conduction velocities. Myelinated fibres were decreased in number in skin biopsy specimens in our patients and in peripheral nerve biopsy specimens of other patients. ${ }^{41217}$ These findings indicate a neuronopathy or an axonopathy of the centrifugal sensory axons as the underlying pathology. ${ }^{20}$ Additional involvement of centripetal axons of sensory neurons was found in hexosaminase $A$ and $B$ deficient patients with sensory loss. ${ }^{121417}$ Postmortem examination in one of them, with a spinocerebellar syndrome in addition to decreased vibratory sensation in the arms and legs and slightly decreased position sense in the toes, showed almost complete degeneration of the posterior columns. ${ }^{1314}$ Cervical cord MRI performed in one of our patients suggested posterior column degeneration, showing flattening of the posterior contour, in addition to generalised cord atrophy (figure, A, B). The topographic pattern of sensory loss in our patients, exemplified in patient 3 who had decreased pinprick and temperature sensation all over her body except on her face and back, is indicative of an advanced length dependent distal polyneuropathy. ${ }^{21}$ This is surprising, because it might be expected the characteristic primary neuronal ganglioside accumulation of $\mathrm{G}_{\mathrm{M} 2}$-gangliosidosis to be associated with prominent short fibre damage, thereby resulting in more severe proximal sensory loss, and, in the motor system, in a proximal limbgirdle syndrome. The last was indeed present in our patients and is typical for $\mathrm{G}_{\mathrm{M} 2}$-gangliosidosis. ${ }^{4-19}$ Different pathomechanisms might therefore be involved in affected sensory and spinal motor neurons. Gangliosides are transported by fast anterograde axonal flow to the nerve terminals ${ }^{22}$ and it is likely that excessive ganglioside accumulation in neuronal sensory perikarions interferes with the axonal transport of substances such as nutritive and trophic factors. The distal endings of the longest axons are most vulnerable and most likely to degenerate first, resulting in a length dependent dying back axonopathy.

Our patients and a review of the medical literature show that significant sensory impairment has not been reported in hexosaminase A deficiency and possibly is linked to hexosaminase A and B deficiency (table 1). The patients reported extend the phenotype of hexosaminidase $A$ and $B$ deficiency (Sandhoff disease) by the presentation of early and prominent sensory disturbances, especially mechanoallodynia, which may be the manifesting symptom of the disease.

We thank Dr W Wichmann, Department of Neuroradiology, University Hospital, Zürich, for the neuroimaging studies and Dr P Isler, Department of Neurology, University Hospital Zürich for performing some of the electrodiagnostic studies.

1 Gravel RA, Clarke JTR, Kaback MM, et al. The $\mathrm{G}_{\mathrm{M}_{2}}$ gangliosidoses. In Scriver CR, et al, eds. The metabolic bases of inherited disease. 7th ed. New York: McGraw-Hill, of inherited disease.

2 Federico A, Palmeri S, Malandrini A, et al. The clinical aspects of adult hexosaminidase deficiencies. Dev Neurosci 1991;13:280-7. 
3 Johnson WG. The clinical spectrum of hexosaminidase deficiency diseases. Neurology 1981;31:1453-6.

4 Mitsumoto H, Sliman RJ, Schafer IA, et al. Motor neuron disease and adult hexosaminidase A deficiency in two
families: evidence for multisystem degeneration. Ann families: evidence for

5 Rapin I, Suzuki K, Suzuki K, et al. Adult (chronic) $\mathrm{G}_{\mathrm{M} 2}$ gangliosidosis. Arch Neurol 1976;33:120-30.

6 Willner JP, Grabowski GA, Gordon RE, et al. Chronic $\mathrm{G}_{\mathrm{M} 2}$ gangliosidosis masquerading as atypical Friedreich ataxia: clinical, morphological and biochemical studies of nine cases. Neurology 1981;31:787-98.

7 Navon $R$, Argov Z, Brand N, et al. Adult $\mathrm{G}_{\mathrm{M}_{2}}$ gangliosidosis in association with Tay Sachs disease: a new phenotype. Neurology 1981;31:1397-401.

8 Argov $Z$, Navon $R$. Clinical and genetic variations in the syndrome of adult $\mathrm{G}_{\mathrm{M} 2}$ gangliosidosis resulting from hexosaminidase A deficiency. Ann Neurol 1984;16: 14-20.

9 Johnson WG, Wigger HJ, Karp HR, et al. Juvenile spinal muscular atrophy: a new hexosaminidase deficiency muscular atrophy: a new hexosamin
phenotype. Ann Neurol 1982;11:11-6.

10 Harding AE, Young EP, Schon F. Adult onset supranuclear ophthalmoplegia, cerebellar ataxia, and neurogenic proximal muscle weakness in a brother and sister: another hexosaminidase A deficiency syndrome. I Neurol Neurosurg Psychiatry 1987;50:687-90.

11 Hardie RJ, Young EP, Morgan-Hughes JA. Hexosaminidase A deficiency presenting as juvenile progressive dystonia. $\mathcal{F}$ Neurol Neurosurg Psychiatry 1988;51: 446-7.

12 Cashman NR, Antel JP, Hanock LW, et al. N-Acetylhexosaminidase-locus defect and juvenile motor neuron disease: a case study. Ann Neurol 1986;19:568-72.

13 Oonk JGW, Van der Helm HJ, Martin JJ. Spinocerebellar degeneration: hexosaminidase $A$ and $B$ deficiency in two degeneration: hexosaminidase A and B
adult sisters. Neurology 1979;29:380-4.

14 Bolhuis PA, Oonk JGW, Kamp PE, et al. Ganglioside storage, hexosaminidase lability, and urinary oligosac- charides in adult Sandhoff's disease. Neurology 1987; 37:75-81.

15 Barbeau A, Plasse $L$ Cloutier $T$, et al Lysosoma enzymes in ataxia: discovery of two new cases of late onset hexosaminidase $\mathbf{A}$ and $\mathbf{B}$ deficiency (adult Sandhoff disease) in French Canadians. Can 7 Neurol Sandhoff disease) in

16 Federico A, Ciacci G, d'Amore $I$, et al. $\mathrm{G}_{\mathrm{M} 2}$ gangliosidosis with hexosaminidase $A$ and $B$ defect: report of a family with motor neuron disease-like phenotype. $f$ Inher Metab Dis 1986;9(suppl 2):307-10

17 Mondelli M, Rossi A, Paleri S, et al. Neurophysiological study in chronic $\mathrm{G}_{\mathrm{M} 2}$ gangliosidosis (hexosaminidase A and $B$ deficiency), with motor neuron disease phenotype. Ital F Neurol Sci 1989;10:433-9.

18 Mitsuo $\mathrm{K}$, Nakano $\mathrm{T}$, Kobayashi $\mathrm{T}$, et al. Juvenile Sandhoff disease: a Japanese patient carrying a mutation identical to that found earlier in a Canadian patient. $\mathcal{F}$ Neurol Sci 1990;98:277-86.

19 Rubin M, Karpati G, Wolfe LS, et al. Adult onset motor neuron disease in the juvenile type of hexosaminidase A neuron disease in the juvenile type of hexosaminid
and B deficiency. $\mathcal{F}$ Neurol Sci 1988;87:103-19.

20 Dalakas MC. Chronic idiopathic ataxic neuropathy. Ann Neurol 1986;19:545-54.

21 Sabin ThD. Classification of peripheral neuropathy: the long and the short of it. Muscle Nerve 1986;9:711-9.

22 Leeden RW, Skrivanek JA, Nunez J, et al. Implications of the distribution and transport of gangliosides in the nervous system. In Rapport MM, Gorio A, eds. Gangliosides in neurological and neuromuscular function, development and repair. New York: Raven Press, 1981:211.

23 Inui $\mathrm{K}$, Wenger DA. Usefulness of 4-methylumbelliferyl6-sulfo-2-acetamido-2-deoxy- $\beta$-D-glucopyranoside for the diagnosis of GM2-gangliosidoses in leukocytes. Clin Genet 1984;26:318-21.

24 Bayleran J, Hechtman P, Saray W. Synthesis of 4-methylumbelliferyl- $\beta-D-N$-acetylglucosamine-6-sulfate and its use in classification of $\mathrm{G}_{\mathrm{M}_{2}}$-gangliosidosis genotypes.
Clin Chim Acta 1984;143:73-89. 